\title{
HIDROTERMALISMO NO COMPLEXO GRANITICO LAVRAS E VULCÂNICAS ASSOCIADAS, RS
}

\author{
LAURO VALENTIM STOLL NARDI* e EVANDRO FERNANDES DE LIMA*
}

\begin{abstract}
HYDROTHERMAL ALTERATION IN THE LAVRAS GRANITE COMPLEX AND ASSOCIATED VOLCANIC ROCKS, RS. The gold-sulphide mineralization in the Lavras do Sul region (RS) is associated with propilitization, sericitization, and silicification of host rocks. These hydrothermal alterations are evident in the Lavras Granite Complex and volcanoclastic rocks. Episyenites and beresites have been identified among the hydrothermal products. Majors and traces elements distribution in granitic rocks have been extensively affected just where the hydrothermal alternation is extremely well-developed reaching its most advanced stages. Loss on ignition, representing the amount of volatile elements, is the best indicator of hydrothermal alteration intensity, particularly in the propilitized and sericitized materials. In the granitic rocks, $\mathrm{Au}, \mathrm{Ag}$, and $\mathrm{As}$ are the best pathfinders for lithogeochemical exploration. $\mathrm{K}_{2} \mathrm{O}$ and $\mathrm{Na}_{2} \mathrm{O}$ show sharp decrease near the mineralized zones in the Merita area. REE had low mobility during the hydrothermal event identified in the Lavras Granite Complex: LREE depletion has been noticed only in deeply altered products as episyenites. REE have been determined in sericite, chlorite, and epidote concentrates. Even though subsurface data are not available, it is possible to suggest a porphyry copper model for this mineralization based upon the possibility of vein mineralization presently known, representing hydrothermal activity in the suprastructure of the main deposit.
\end{abstract}

INTRODUÇÃo O Complexo Granítico de Lavras e a seqüência vulcânica associada foram descritos por Nardi \& Lima (1985), sendo o complexo granítico constituído por uma associação de rochas shoshoníticas e alcalinas conformando um corpo com zonação concêntrica reversa. O núcleo expõe rochas granodioríticas mais antigas (aproximadamente 640 Ma) enquanto pertita granitos (aproximadamente $550 \mathrm{Ma}$ ) dominam ao longo das bordas norte, oeste e sul. Os contatos observados entre esses dois tipos litológicos são gradacionais, constituindo rochas híbridas possivelmente geradas por assimilação das rochas granodioríticas pelo magma alcalino.

A seqüência vulcânica da área da Merita é constituída por rochas piroclásticas relacionadas a fall deposits, onde predominam os termos tufáceos intercalados com lavas andesíticas e níveis subordinados de ignimbritos (flow deposits). Essas litologias, bem como a porção central do Complexo Granítico de Lavras são de afinidade shoshonítica e provavelmente contemporâneas. As rochas vulcânicas desta região são referidas no presente trabalho como pertencentes à Formação Hilário (Ribeiro \& Fantinel 1978).

Nos tipos litológicos descritos ocorre mineralização sulfetada com importantes concentraçōes de ouro, cobre, chumbo, zinco e prata parcialmente exploradas para extração de ouro desde o início deste século e são descritas por Teixeira \& Leinz (1942), Goñi (1961) e Reischel (1980), entre outros autores. Molibdenita ocorre em fraturas nos granodioritos do núcleo do Complexo Granítico de Lavras. Nardi (1984) apresentou dados analíticos relacionados principalmente com a alteração hidrotermal associada à mineralização, discutindo algumas hipóteses genéticas. De acordo com os autores citados, a maior parte da mineralização até agora conhecida está relacionada com veios de quartzo de possança variável, portadores de sulfetos de cobre, chumbo e zinco, além de pirita aurífera.

Nas rochas graníticas e vulcânicas próximas, a mineralização é predominantemente de sulfetos de $\mathrm{Cu}-\mathrm{Fe}$ contendo ouro. Sulfetos de chumbo e zinco com prata associada são observados principalmente nas porções mais distantes da intrusão granítica, isto é, nas porções superiores da seqüência vulcânica. Nos pertita granitos a mineralização aparece em zonas cataclásticas intensamente hidrotermalizadas com pirita aurífera disseminada e veios de quartzo portadores de ouro refe- ridos por Teixeira \& Leinz (1942).

A zona de oxidação de parte desses filōes foi explorada desde o fim do século passado durante aproximadamente meio século. Estima-se que tenham sido produzido em torno de 100 $\mathrm{kg}$ de ouro. Reischel (1980), reportando estudos mais recentes nas zonas cataclasadas que cortam os pertita granitos, sugere teores médios de ouro da ordem de $2,5 \mathrm{~g} / \mathrm{t}$, embora Teixeira \& Leinz (1942) descrevam concentrações locais de até $100 \mathrm{~g} / \mathrm{t}$.

O presente trabalho, com base em amostras de superfície e de subsuperfície, como no caso das amostras de rochas vulcânicas, tem como objetivo apresentar características gerais dos produtos da alteração hidrotermal observados em algumas das mineralizações do complexo granítico e da área de Volta Grande, na mina da Merita, provavelmente situada nas porçỏes mais superiores da Formação Hilário, bem como discutir algumas hipóteses genéticas e suas implicações na potencialidade metalogenética desta região. Salientamos que trabalhos futuros com acesso a um número maior de amostras de sondagens, particularmente nas rochas graníticas, poderão complementar e expandir em muito os conceitos aqui abordados.

ALTERAÇÃo HIDROTERMAL O Complexo Granítico de Lavras (Fig. 1) tem um núcleo constituído por rochas dominantemente granodioríticas, suas fases máficas são anfibólios (ferro-edenitas) e biotitas, ocorrendo como acessórios esfeno, zircão, apatita, magnetita titanífera e alanita, além de rara fluorita. Os pertita granitos são constituídos por mesopertita, quartzo, anfibólio (ferro-edenita com alta razão $\mathrm{Fe} / \mathrm{Mg}$ ), zircâo, fluorita, alanita, apatita, biotita, esfeno, magnetita e ilmenita. As rochas híbridas possuem composição intermediária entre os dois tipos extremos, sendo observáveis todos os tipos transicionais. A textura rapakivi presente no núcleo e nos termos transicionais é atribuída a processos de assimilação preconizados por Nardi (1984). Nas litologias de núcleo e transicionais, a mineralização conhecida é contida em veios de quartzo ocorrendo também preenchimento de fraturas por molibdenita, particularmente no núcleo do complexo. No local denominado Fazenda da Chácara a alteração hidrotermal é muito intensa nos granodioritos e monzogranitos, ocorrendo também calcopirita. Não se dispõe de dados a respeito da mineralização associada uma vez que os trabalhos de prospecção estão paralisados. Trabalhos de campo nas zonas 
próximas desses veios mostraram que os plagioclásios e minerais máficos tendem a assumir uma coloração esverdeada, os feldspatos alcalinos se tornam avermelhados e constata-se a presença eventual de pirita. Estudos microscópicos mostram a presença de alteração propilítica (Rose \& Burt 1979) estendendo-se até algumas dezenas de metros dos veios. Anfibólios e biotitas são substituídos por clorita + epídoto \pm calcita. Em geral a alteração dos anfibólios é mais intensa que a das biotitas. Plagioclásios são sericitizados e albitizados, e os feldspatos alcalinos se tornam turvos provavelmente pela formação de hematita submicroscópica nas superfícies dos grãos relacionada com a oxidação do ferro ferroso para férrico. Os minerais acessórios são grandemente preservados; carbonatação pode estar registrada em fases portadoras de cálcio: e a piritização é escassa. Turmalina e rutilo são observados em algumas amostras.
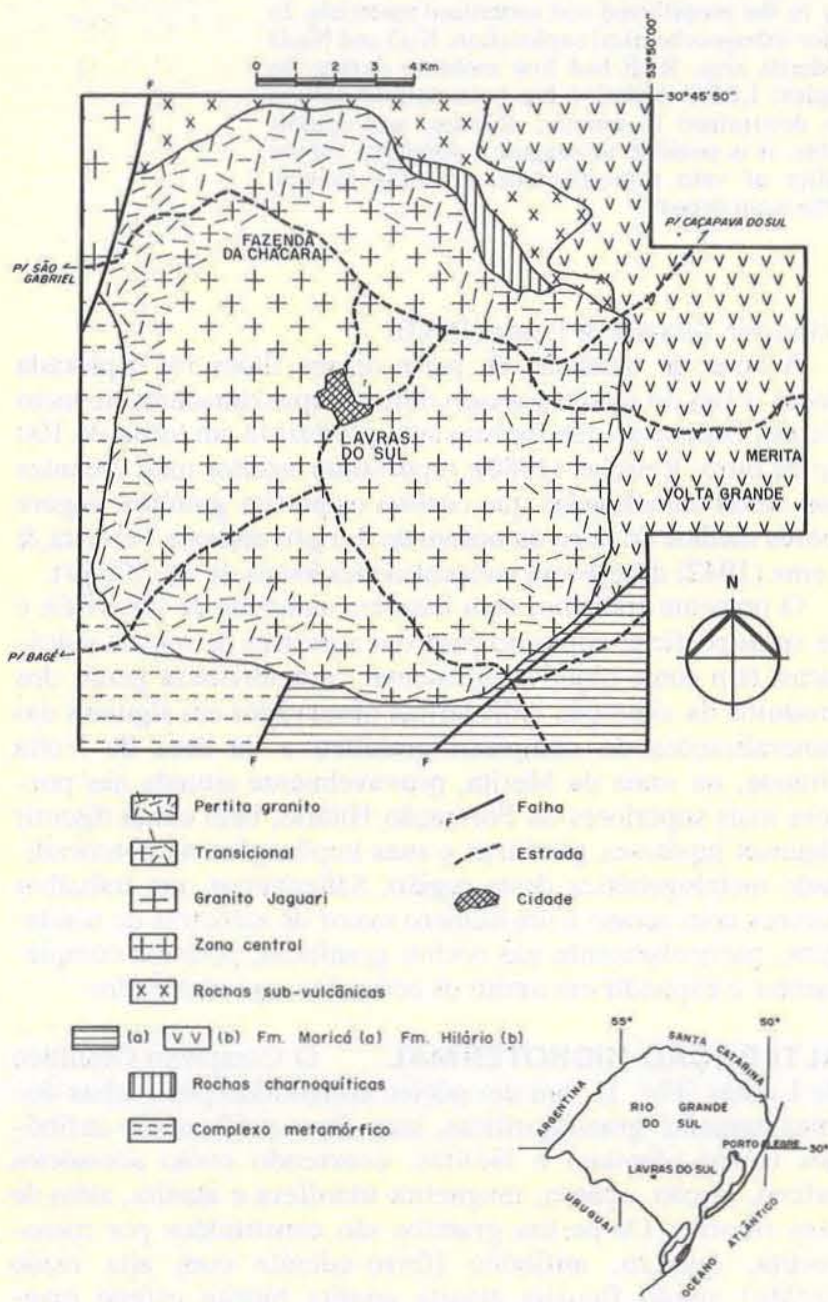

Figura 1 - Mapa geológico simplificado do Complexo Granítico Lavras e vulcânicas associadas

Nas porçōes mais próximas dos veios, a sericitização se torna dominante: a clorita é substituída por moscovita e óxidos de ferro, a calcita é mais abundante, tanto substituindo minerais portadores de cálcio como preenchendo fraturas. $\mathrm{O}$ conteúdo de pirita se torna maior e os feldspatos alcalinos, mais turvos. Essas transformações geram as colorações esverdeadas e o avermelhamento dos feldspatos, feiçōes indicadoras da presença dos veios mineralizados. O estágio mais avançado dessa atividade hidrotermal gera rochas esverdeadas constituídas por quartzo-sericita-calcita com sulfetos dissemi- nados e cortados por veios de quartzo. Zircão e apatita são preservados durante o hidrotermalismo e a piritização atinge seus mais elevados índices. Rochas desprovidas de quartzo e constituídas por calcica + pirita + sericita \pm albita foram reconhecidas na área da Fazenda da Chácara associadas à mineralização com calcopirita. Tais hidrotermalitos são denominados beresitos pelos pesquisadores soviéticos (Boyle 1979) e a presença de fluorita nos beresitos de Lavras do Sul indica uma alta atividade de flúor durante este estágio hidrotermal, ao contrário do que é geralmente reportado nesse tipo de alteração.

Agregados de anfibólio (provavelmente actinolita) com cristais de até uma dezena de centímetros ocorrem junto a zonas hidrotermalizadas e com mineralização de $\mathrm{Cu}$ - $\mathrm{Au}$ na porção leste do Complexo Granítico de Lavras. A presença de actinolita entre produtos do hidrotermalismo tem sido referida por vários autores, entre os quais John (1975), reportando-se à alteração propilítica em Bingham, Rose \& Burt (1979) descrevendo a mineralização do tipo cobre pórfiro do distrito de Big Bug, Arizona, EUA.

Nos pertita granitos, a mineralização ora considerada é constituída por pirita disseminada em zonas cataclásticas profundamente hidrotermalizadas, gerando rochas de coloração verde e granulação fina que, sob a ação do intemperismo, tornam-se amareladas. Teixeira \& Leinz (1942) denominaram esses hidrotermalitos minério pirítico, observando que os mesmos possuem elevadas concentrações de ouro. $\mathrm{O}$ minério pirítico grada mais ou menos rapidamente para o pertita granito que junto ao contato mostra-se com os feldspatos avermelhados e um pouco de pirita disseminada. Segundo Teixeira \& Leinz (op cit.), esse minério pode constituir corpos lenticulares ou irregulares com até $50 \mathrm{~m}$ de espessura. A alteração propilítica, que se desenvolveu nos pertita granitos nas proximidades dos corpos de minério pirítico, é identificada pelo turvamente dos feldspatos alcalinos, transformação dos anfibólios em clorita + carbonato + epídoto e preenchimento de fraturas por calcita.

Com o avanço do processo hidrotermal, o ortoclásio das pertitas é sericitizado antes da albita. Cloritas, epídotos e mesmo quartzo são também transformados. São gerados dessa forma beresitos constituídos por sericita + pirita \pm carbonato.

Foram encontrados pertita granitos com as pertitas turvas e o quartzo completamente substituído por calcita gerando rochas denominadas episienitos (Strong 1982). A alta atividade de $\mathrm{CO}_{2}$ sugerida por tais transformaçōes levou Strong (op cit.) a sugerir o termo carbotermal em substituição a hidrotermal. Episienitos têm sido descritos associados a mineralizações de urânio e molibdenita em granitos, sendo mais comum a substituição do quartzo por sericita (Leroy 1978).

Comparando as porções alteradas hidrotermalmente nas rochas graníticas de Lavras do Sul, consideradas neste trabalho, pode-se concluir que nos hidrotermalitos desenvolvidos a partir das rochas de núcleo e transicionais o quartzo é mais abundante, tanto sob a forma de veios, como disseminado nos produtos de alteração. Nesses hidrotermalitos, a propilitização é mais evidente, sendo acompanhada por pirita, calcopirita, galena, blenda e outros sulfetos, além de molibdenita, principalmente em fraturas. As mineralizações se distribuem tanto em veios de quartzo como em porçôes afetadas por cataclase.

$\mathrm{Na}$ área da Merita, o estudo petrográfico de amostras de superfície e subsuperfície ( 11 furos de sondagem) permitiu reconhecer que as fases hidrotermais se distribuem na matriz das rochas vulcânicas e piroclásticas além de substituir parcial e totalmente os piroclastos e fenocristais. A presença de veios e microveios constituídos por quartzo, carbonato, epídoto e mais raramente por anfibólio, opticamente identificado como actinolita, é também comum. Um padrão de alteração hidrotermal semelhante é constatado no conglomerado vulcânico de arcabouço andesítico e matriz lítica, que representa a porção 
superior na área da Merita.

Nas rochas vulcânicas, texturalmente porfiríticas, observa-se a transformação do plagioclásio para epídoto (pistacita) e albita, esta última geralmente na forma de anéis em torno dos fenocristais. Os minerais máficos são por vezes parcialmente preservados, sendo comum a alteração do clinopiroxênio para clorita, do anfibólio, opticamente reconhecido como do grupo das hornblendas, para clorita, biotita e minerais opacos. A olivina é rara e ocorre nos termos mais básicos da seqüência vulcânica, sendo transformada em serpentina ou carbonato. $\mathrm{O}$ mineral acessório predominante é apatita, que não mostra modificações que possam ser constatadas petrograficamente. $\mathrm{O}$ esfeno ocorre de forma menos freqüente e pode estar modificado para uma associação de minerais opacos e uma "massa" descrita genericamente como leucoxênio. Observa-se, além das fases acima descritas, a presença subordinada de sericita e argilo-minerais, além de processos de oxidação que são responsáveis pelo tom avermelhado observado em algumas amostras.

Os minerais hidrotermais acima descritos permitem enquadrar a alteração da seqüência vulcânica da área da Merita como do tipo propilítica. Este tipo de alteração está presente em toda a região de Volta Grande. A mineralização na referida área é constituída principalmente por galena, por vezes enriquecida em prata, como se constatou quimicamente e através de seções polidas, pirita aurífera, blenda e subordinadamente calcopirita. A mineralização possui um condicionamento estrutural semelhante ao do Complexo Granítico de Lavras, restringindo-se principalmente às zonas cataclasadas de direção N70W e E-W, e mais raramente, de forma disseminada, às zonas próximas a essas estruturas. Kaul \& Zir Fo (1974) classificaram a mineralização associada às rochas vulcânicas desta região como do tipo filoneana e disseminada. Nessas rochas é também comum a presença de diques de composição intermediária e veios de quartzo ou carbonato. A ganga que acompanha a mineralização é constituída por clorita, quartzo, por vezes carbonato, e epídoto. A presença de anfibólio, provavelmente actinolita, também é constatada, porém este mostra um avançado estado de alteração. O tipo de associação de minerais de minério e o controle estrutural desses é semelhante ao descrito por Berman (1973) e Cuddy \& Kessler (1982), entre outros, para mineralizaçōes filoneanas e do tipo cobre pórfiro.

\section{MÉTOdos ANALÍticos As análises de elementos} maiores e da maior parte dos traços foram executadas por espectrometria de plasma em laboratórios da Universidade de Londres após ataque com ácidos fluorídrico e perclórico. As amostras de rochas vulcânicas foram analisadas no Laboratório de Geoquímica do Instituto de Geociências da UFRGS por espectrometria de fluorescência de raios-X e absorção atômica.

Os elementos terras-raras (ETR), foram determinados por espectrometria de plasma sob a supervisão do Dr. J.N. Walsh nos laboratórios da Universidade de Londres, onde também foram executadas as determinações de As (por absorção atômica com sistenla gerador de hidretos), $\mathrm{Ag}$ (por espectrometria de plasma) e Au, utilizando-se extração com MIBK e leituras por espectroinetria de absorção atômica. A metodologia analítica utilizada, bem como os métodos de separação de minerais e parâmetros utilizados nos trabalhos com microssonda eletrônica, está registrada por Nardi (1984) e Lima (1985).

\section{DISTRIBUIÇÃO DE ELEMENTOS MAIORES E TRA-}

ÇOS Análises químicas para elementos maiores e traços de 10 amostras graníticas propilitizadas (Tab. 1) indicaram que, em relação às médias das rochas inalterada referidas por Nardi (1984) (Tab. 2), são destacáveis as seguintes variações:

- decréscimo de $\mathrm{CaO}$ quando a atividade de $\mathrm{CO}_{2}$ é baixa;

- decréscimo de $\mathrm{MgO}$;

- empobrecimento em Li;
- As e $\mathrm{Cu}$ apresentam teores variáveis, podendo atingir altas concentrações;

- Au é enriquecido em algumas amostras;

- aumento da quantidade de voláteis expresso nas determinações de perda ao fogo.

Nos pertita granitos, a única modificação importante gerada pela propitilização é a redução dos teores de Li.

$\mathrm{O}$ desaparecimento da clorita e conseqüente formação de sericita + pirita, conforme já descreveram Meyer \& Hemley, (1967), foi considerado como divisório entre o processo de propilitização e sericitização, com base em Rose \& Burt (1979). Nas amostras sericitizadas constataram-se as seguintes variações químicas em relação às amostras inalteradas:

- empobrecimento do $\mathrm{CaO}$, a menos que os carbonatos sejam abundantes;

- enriquecimento relativo de $\mathrm{K}_{2} \mathrm{O}$ nos estágios mais avançados da sericitização;

- aumento dos voláteis traduzido nas determinações de perda ao fogo;

- $\mathrm{Cu}, \mathrm{Pb}$ e $\mathrm{Zn}$ atingem altos teores quando os sulfetos estão presentes;

- empobrecimento de $\mathrm{Li}$ e $\mathrm{Sr}$.

Ressalta-se ainda que o minério pirítico pode conter altos teores de ouro (em torno de $5 \mathrm{ppm}$ ), observando-se neste caso enriquecimento de As e Mo além de Ag. Nas amostras fortemente sericitizadas, o teor de $\mathrm{Al}_{2} \mathrm{O}_{3}$ cresce em detrimento de $\mathrm{SiO}_{2}$. $\mathrm{CaO}$ e $\mathrm{Na}_{2} \mathrm{O}$ sofrem grande redução enquanto $\mathrm{K}_{2} \mathrm{O}$ e perda ao fogo (voláteis) aumentam substancialmente, e Li e $\mathrm{Rb}$ podem apresentar enriquecimento. Altos teores de $\mathrm{Zr}$ parecem refletir a elevada resistência do zircão aos processos de alteração hidrotermal.

Na seqüência vulcânica da área da Merita, a comparação entre as médias e o padrão de distribuição de alguns elementos maiores e traços entre rochas inalteradas (Lima \& Nardi 1985) e hidrotermalmente alteradas (Lima op. cit.), como mostra a figura 2, revelou os seguintes aspectos:

- Os teores de $\mathrm{Cu}$ e $\mathrm{Zn}$ são muito semelhantes nos dois grupos de amostras enquanto o $\mathrm{Pb}$ é empobrecido nas rochas hidrotermalizadas;

- $\mathrm{Na}_{2} \mathrm{O}$ e $\mathrm{K}_{2} \mathrm{O}$ possuem teores semelhantes entre as amostras comparadas com enriquecimento de $\mathrm{K}_{2} \mathrm{O}$ nas amostras mais afetadas pelo hidrotermalismo;

- $\mathrm{MgO}$ apresenta um leve enriquecimento nas amostras hidrotermalizadas;

- $\mathrm{Fe}_{2} \mathrm{O}_{3}(\mathrm{t})$ possui teores semelhantes para os dois conjuntos de amostras;

- $\mathrm{CaO}$ e perda ao fogo apresentam valores expressivamente elevados nas amostras hidrotermalizadas, o que é coerente com a presença abundante de calcita. A elevada perda ao fogo está principalmente vinculada à presença desta fase mineral, sendo a correlação entre $\mathrm{CaO}$ e perda ao fogo nas amostras hidrotermalizadas próxima a 1 .

A comparação entre amostras hidrotermalizadas sem mineralização com quatro amostras mineralizadas permitiu reconhecer uma sensível diminuição de $\mathrm{K}_{2} \mathrm{O}+\mathrm{Na}_{2} \mathrm{O}$ nestas últimas.

Com o objetivo de investigar o comportamento de alguns elementos em função do hidrotermalismo nas rochas graníticas, utilizou-se a análise de fatores empregando-se para tanto o programa Statistical Package for the Social Science (SPSS).

Foram computados os teores de 16 elementos em 34 amostras de rochas propilitizadas, sericitizadas e silificadas, contendo ou não sulfetos. A tabela 3 apresenta os escores dos cinco fatores obtidos após rotação Varimax. Este mesmo método foi utilizado nas rochas vulcânicas da área da Merita e os reusltados obtidos foram discutidos por Lima (1985) e Lima \& Nardi (1985).

$\mathrm{O}$ exame dos fatores obtidos permite sugerir o relacionamento do primeiro fator com o processo de sericitização e piritização, ocasionando aumento dos voláteis (PF), do $\mathrm{K}, \mathrm{Rb}$, 
Tabela 1 - Dados de elementos maiores e traços em amostras hidrotermalizadas do Complexo Granítico Lavras. (n.d. = não determinado; $P=$ amostras de pertita granito hidrotermalizado; $P F=$ perda ao fogo a $900^{\circ} \mathrm{C}$ )

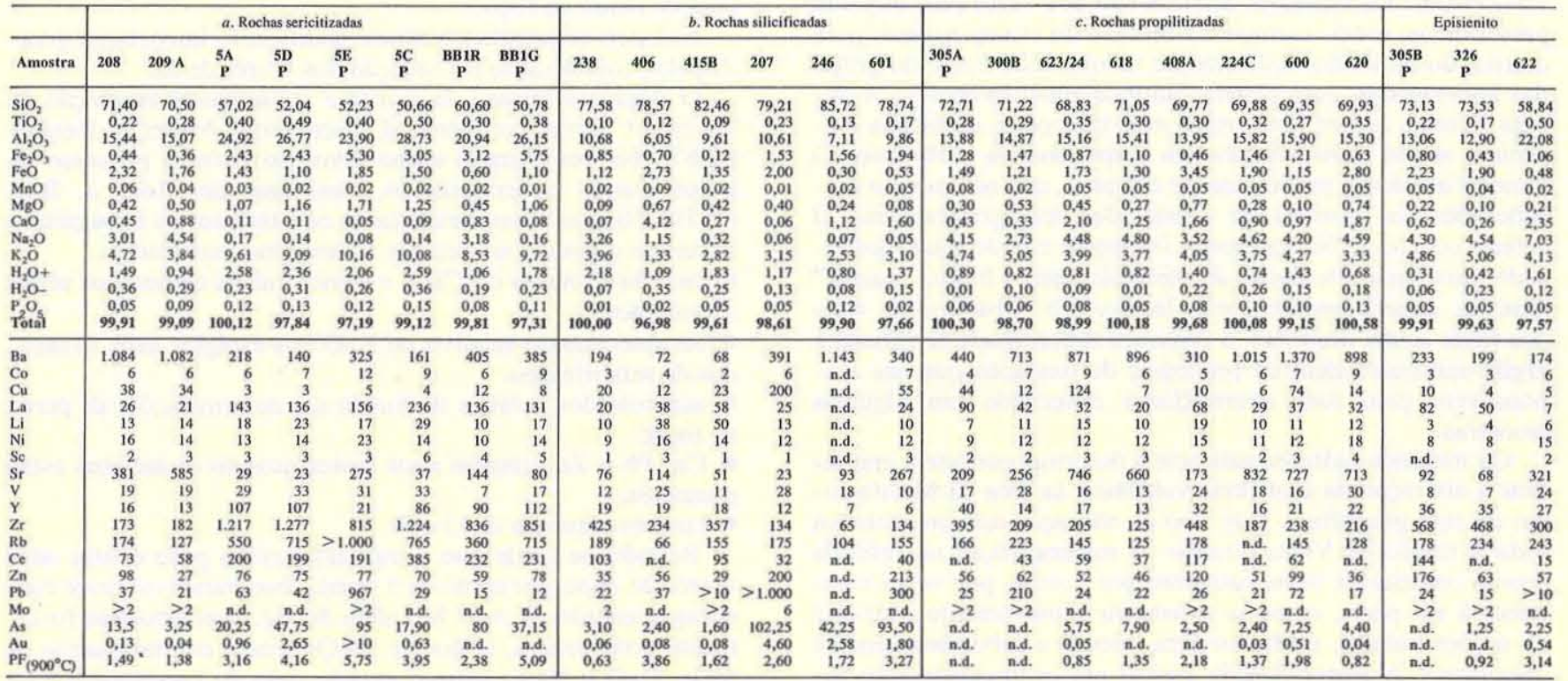

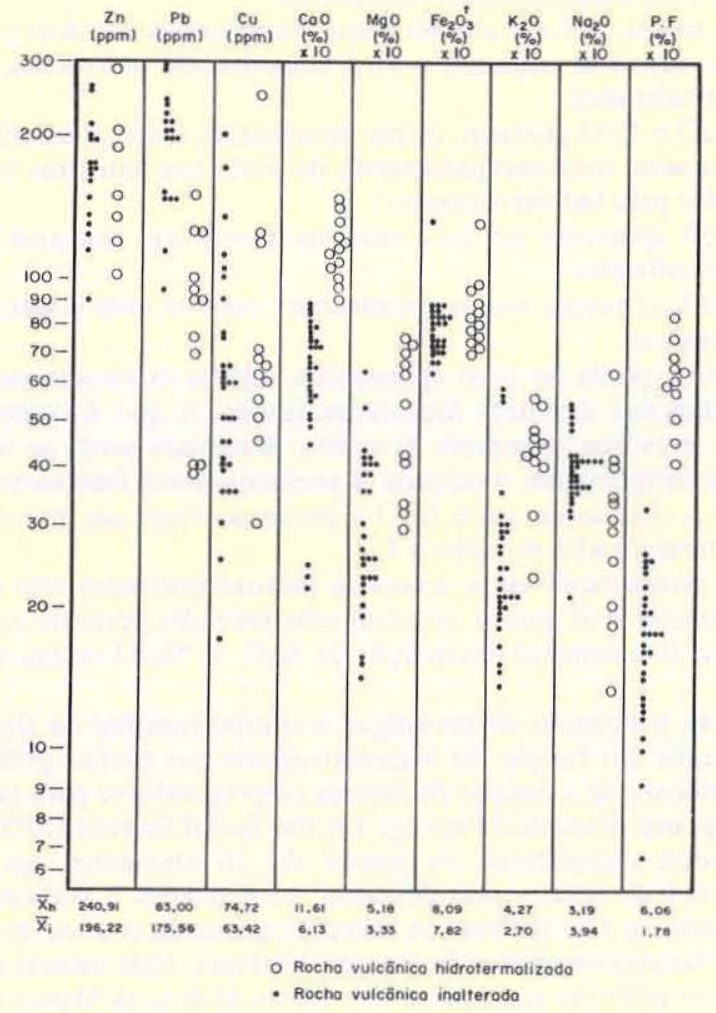

Figura 2 - Comparação entre os teores de elementos maiores e traços em rochas vulcânicas inalteradas e rochas hidrotermalizadas da área da Merita: $\left(\mathrm{x}_{\mathrm{h}}\right)$ média aritmética das rochas vulcânicas hidrotermalizadas; $\left(\overline{\mathrm{x}}_{\mathrm{i}}\right)$ média aritmética das rochas vulcânicas inalteradas
$\mathrm{Fe}, \mathrm{Au}$ e $\mathrm{Mg}$, concomitantemente com empobrecimento em $\mathrm{Ca}$ decorrente da atividade baixa de $\mathrm{CO}_{2}$ em relação às rochas propilitizadas. $\mathrm{O}$ segundo fator pode ser relacionado com a intensidade do hidrotermalismo, refletindo-se no aumento dos voláteis (PF), enriquecimento de $\mathrm{Au}, \mathrm{Ag}, \mathrm{As}$ e perda de $\mathrm{Na}$, e indicando uma tendência de $\mathrm{Au}$ e $\mathrm{Ag}$ se concentrarem onde a alteração hidrotermal foi mais pronunciada, sendo o As um bom indicador geoquímico. $\mathrm{O}$ terceiro fator parece relacionar-se com a distribuição dos elementos calcófilos: $\mathrm{Cu}, \mathrm{Pb}, \mathrm{Zn}$ e $\mathrm{Ag}$, que, de acordo com esta interpretação, não mostram correlação com a distribuiçăo do Au. O quarto e quinto fatores são possíveis de relacionamento com a composição química original das rochas hidrotermalizadas, refletindo assim a variação entre os tipos granodiorítico, transicional e alcalino.

As relações entre os teores dos elementos analisados com uma quantidade variável de amostras (200 para a maioria, 46 para $\mathrm{As}$ e $\mathrm{Ag}$, e 35 para $\mathrm{Au}$, foram também interpretadas com base em estudos de correlação ordinal pela determinação do coeficiente de Spearmann. Com base nas constatações acima apresentadas, sugere-se que sejam considerados, no desenvolvimento de metodologias para prospecção litogeoquímica nas rochas graníticas, os seguintes aspectos:

- os melhores indicadores geoquímicos das mineralizaçōes auríferas são $\mathrm{Ag}$ e As além do próprio $\mathrm{Au}$; o $\mathrm{Pb}$ pode ser utilizado para a maior parte dos casos considerados;

- o aumento dos valores de perda ao fogo dá ótima indicação da intensidade do hidrotermalismo, sendo portanto um bom indicador geoquímico das mineralizaçōes;

- $\mathrm{Cu}$ e $\mathrm{Zn}$ sâo indicadores geoquímicos utilizáveis na prospecção das mineralizações enriquecidas em sulfetos desses elementos;

- os halos geoquímicos identificados neste trabalho são relativamente estreitos; malhas para amostragem litogeoquímica devem portanto ter pouco espaçamento, em torno de $20 \mathrm{~m}$.

As mineralizações nos pertita granitos se mostraram de 
mais difícil detecção pelos métodos geoquímicos testados, principalmente devido à redução do tamanho dos halos de dispersão.

Várias razões entre elementos como $\mathrm{Mg} / \mathrm{Li}, \mathrm{K} / \mathrm{Rb}, \mathrm{Ba} / \mathrm{Rb}$ e outras foram testadas tendo em vista sua utilização na detecção :das mineralizaçōes. Os resultados obtidos indicam que suas variaçöes refletem primordialmente a distribuição origi-

Tabela 2 - Médias e desvios-padrão dos teores de elementos maiores e traços nos granitóides sem alteração hidrotermal da zona central (ZC), transicionais (TR) e pertita granitos $(P G)$ do Complexo Granítico Lavras. Número de amostras computadas entre parênteses

\begin{tabular}{|c|c|c|c|c|c|c|}
\hline \multirow[b]{2}{*}{ \% Peso } & \multicolumn{3}{|c|}{ Médias } & \multicolumn{3}{|c|}{ Desvios-padrão } \\
\hline & zC & TR & PG & $\mathrm{zC}$ & TR & PG \\
\hline $\mathrm{SiO}_{2}$ & $70,18(14)$ & $70,70(9)$ & $73,12(8)$ & 0,54 & 1,01 & 0,80 \\
\hline & $15,24(14)$ & $14,21(9)$ & & & & \\
\hline $\mathrm{TiO}_{2}$ & $0,32(48)$ & $0,31(29)$ & $0,21(4)$ & 0,04 & 0,0 & 03 \\
\hline $\mathrm{Fe}_{2} \mathrm{O}_{3}$ (tot.) & $2,84(4$ & $3,34(29)$ & $3,08(40)$ & 0,39 & 0,3 & 0 \\
\hline $\mathrm{Fe}_{2} \mathrm{O}_{3}$ & $0,27(13$ & $0,75(8)$ & 0,50 & 0,29 & 0,40 & 28 \\
\hline $\mathrm{FeO}$ & $2,30(13$ & $2,29(8)$ & $2,23(8)$ & 0,22 & 0,33 & 0,32 \\
\hline $\mathrm{MgO}$ & $0,61(48)$ & $0,44(29)$ & $0,17(40)$ & 0,08 & 0,2 & 07 \\
\hline $\mathrm{CaO}$ & $1,79(48)$ & $0,87(29)$ & $0,31(40)$ & 0,2 & 0,4 & 0,18 \\
\hline $\begin{array}{l}\mathrm{Na}_{2} \mathrm{O} \\
\mathrm{K}=\mathrm{O}\end{array}$ & $\begin{array}{l}4,45(48) \\
3,78(48)\end{array}$ & $4,01(29)$ & $4,16(40)$ & & & 0,30 \\
\hline $\begin{array}{l}\mathrm{K}_{2} \mathrm{O} \\
\mathrm{MnO}\end{array}$ & $\begin{array}{l}3,78(48) \\
0.04(48)\end{array}$ & $\begin{array}{l}4,44(29) \\
0,05(29)\end{array}$ & $\begin{array}{l}4,88(40) \\
0,04(40)\end{array}$ & 0,41 & $\begin{array}{l}0,74 \\
0,03\end{array}$ & 0,33 \\
\hline $\mathrm{P}_{2} \mathrm{O}_{5}$ & $\begin{array}{l}0,4(40) \\
0,10(48)\end{array}$ & , $10(29)$ & $\left.\begin{array}{l}0,04(40) \\
0,05(40)\end{array}\right]$ & 0,01 & 0,0 & 0,01 \\
\hline $\begin{array}{l}2 \mathrm{O}^{5} \\
\text { P. F. }\end{array}$ & 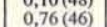 & 0 & $0,59(40)$ & 0,16 & $\begin{array}{l}0,03 \\
0,19\end{array}$ & $\begin{array}{l}0,02 \\
0,17\end{array}$ \\
\hline $\mathrm{em}_{\mathrm{Ba}} \mathrm{ppm}$ & & & & 54 & & \\
\hline & & $\left.\mid \begin{array}{ll}400 & (29) \\
246 & (29)\end{array}\right]$ & $\begin{array}{rr}190 \\
90 & (40)\end{array}$ & & & $\begin{array}{l}46,0 \\
91,0\end{array}$ \\
\hline & 143 (14) & 208 (9) & $200 \quad(8)$ & 22 & & \\
\hline & 197 (14) & 407 (9) & $535(8)$ & 46. & & \\
\hline $\mathrm{La}$ & $35(48)$ & $\begin{array}{ll}53 & (29)\end{array}$ & 63 (40) & & 21,0 & \\
\hline & (48) & 82 & $3(3$ & & & \\
\hline & (48) & $\begin{array}{ll}35 & (29)\end{array}$ & $37 \quad(40)$ & 13. & & 11,0 \\
\hline $\mathrm{Li}$ & $30 \quad(48)$ & 25 (29) & $10(40)$ & & & 7,7 \\
\hline & $3,4(48)$ & $3,0(29)$ & $1,8(40)$ & & & 0,65 \\
\hline $\mathrm{Ni}$ & $15(48)$ & 15 (29) & $11(40)$ & 2,13 & & 2,1 \\
\hline Co & 8 (48) & 7 (29) & $4,7(40)$ & 1,3 & 1,8 & \\
\hline & $50 \quad(48)$ & $85 \quad(29)$ & $89(40)$ & 21,0 & 33,0 & \\
\hline $\mathrm{Pb}$ & $32 \quad(48)$ & $67 \quad(29)$ & $\begin{array}{ll}28 & (40) \\
& 95\end{array}$ & 42,0 & 179,0 & \\
\hline $\mathrm{Nb}$ & $\begin{array}{ll}17 & (13) \\
23 & (3)\end{array}$ & $\begin{array}{ll}51 & (6) \\
20 & (6)\end{array}$ & $\begin{array}{lll}57 & (8)\end{array}$ & 9,7 & 13,0 & 13,0 \\
\hline $\mathrm{v}$ & $\begin{array}{ll}23 & (35) \\
33 & (47)\end{array}$ & $\left|\begin{array}{ll}22 & (22) \\
19 & (29\end{array}\right|$ & $\left.\begin{array}{ll}13 & (31) \\
12 & (40)\end{array}\right]$ & $\begin{array}{r}4,0 \\
33,0\end{array}$ & $\begin{array}{r}7,0 \\
52,0\end{array}$ & $\begin{array}{r}4,0 \\
25,0\end{array}$ \\
\hline
\end{tabular}

Tabela 3 -Resultados da análise de fatores em dados de 34 amostras com evidências de hidrotermalismo

\begin{tabular}{c|r|r|r|r|r}
\hline Fatores & $\mathbf{1}$ & $\mathbf{2}$ & $\mathbf{3}$ & $\mathbf{4}$ & $\mathbf{5}$ \\
\hline $\mathrm{Au}$ & 0,41605 & $-0,69615$ & 0,09610 & $-0,03191$ & $-0,26860$ \\
$\mathrm{Cu}$ & $-0,31124$ & 0,33985 & 0,35832 & 0,11108 & $-0,04415$ \\
$\mathrm{Zn}$ & $-0,00653$ & 0,11930 & 0,98450 & 0,1363 & $-0,03692$ \\
$\mathrm{~Pb}$ & 0,10137 & 0,16010 & 0,91274 & 0,00753 & $-0,09511$ \\
$\mathrm{Ag}$ & 0,08255 & 0,76346 & 0,40724 & $-0,18103$ & $-0,17999$ \\
$\mathrm{Fe}$ & 0,74056 & 0,34606 & $-0,07039$ & $-0,02479$ & 0,16646 \\
$\mathrm{Mg}$ & 0,55218 & 0,07767 & 0,67785 & 0,5886 & 0,76700 \\
$\mathrm{Ca}$ & $-0,43328$ & $-0,12532$ & $-0,22190$ & 0,33069 & 0,35715 \\
$\mathrm{Na}$ & $-0,18382$ & $-0,71529$ & $-0,26751$ & 0,33855 & $-0,27054$ \\
$\mathrm{~K}$ & 0,93777 & 0,10389 & 0,09469 & $-0,19043$ & $-0,05558$ \\
$\mathrm{P.f.}$ & 0,43045 & 0,65360 & $-0,00582$ & $-0,13238$ & 0,22232 \\
$\mathrm{Ba}$ & $-0,19168$ & $-0,07475$ & 0,27302 & 0,80476 & $-0,06944$ \\
$\mathrm{Li}$ & $-0,03291$ & $-0,07503$ & $-0,10826$ & $-0,05315$ & 0,04195 \\
$\mathrm{Sa}$ & $-0,10677$ & $-0,22819$ & $-0,16954$ & 0,95322 & 0,03799 \\
$\mathrm{As}$ & 0,17499 & 0,86521 & 0,04502 & $-0,06696$ & $-0,10147$ \\
$\mathrm{Rb}$ & 0,88278 & 0,35835 & $-0,03676$ & $-0,18223$ & 0,12429 \\
\hline
\end{tabular}

nal dos elementos nas várias rochas constituintes do Complexo Granítico de Lavras.

COMPORTAMENTO DOS ETR DURANTE A ALTERAÇÃO HIDROTERMAL O conteúdo de ETR em quatro amostras de rochas granodioríticas propilitizadas, três sericitizadas e uma do pertita granito sericitizado está representado na figura 3, normalizado pelo padrão condrítico, conforme os valores sugeridos por Haskin et al. (1968). A comparação desses dados com os padrões das rochas inalteradas (Fig. 4) mostra que de modo geral o hidrotermalismo parece afetar os ETR apenas quando atinge graus extremos como no epitienito LN622, no qual o quartzo foi totalmente substituído e al- bita é o principal feldspato, ocorrendo associada com sericita e carbonato. Observa-se ainda que os ETRP tendem a mostrar um caráter mais imóvel enriquecendo-se relativamente tanto nesta amostra como na LN5E, que também mostra uma forte redução de $\mathrm{SiO}_{2}$. Os ETR foram também determinados em três concentrados de sericita, três de biotita cloritizada + clorita e um de epídoto. Esses resultados foram divididos pelo valor da rocha total, obtendo-se razões variáveis de 0,05 a 1,00 para as sericitas e entre 0,5 e 2,0 para as cloritas + biotitas cloritizadas, constatando-se uma forte anomalia negativa de Eu no último caso. O epídoto mostrou razóes entre 100 e $200 \mathrm{com}$ forte anomalia negativa para Eu. Conclui-se que a mineralogia hidrotermal mostra uma capacidade de concentrar ETR equivalente à das fases ígneas que lhes deram origem no caso da propilitização, particularmente se considerarmos que o zircão, concentrador de ETRP, resistiu ao processo hidrotermal mesmo nos estágios mais avançados.
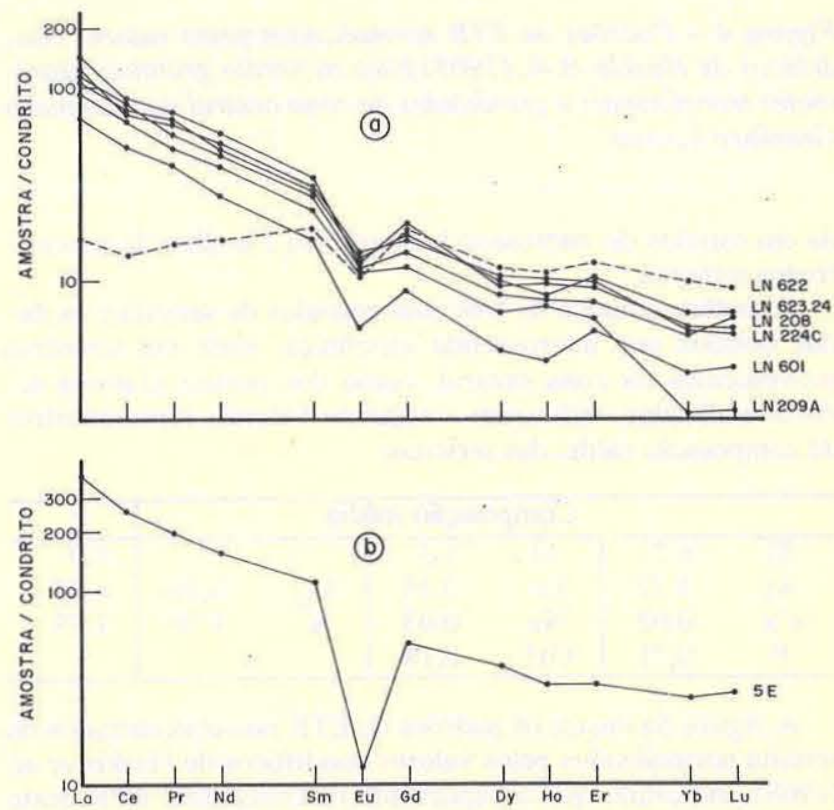

Figura 3 - Padrões de ETR normalizados pelos valores condríticos de amostras hidrotermalizadas do Complexo Granítico Lavras: a. hidrotermalitos da porçâo central - LN622 corresponde a um episienito; b. pertita granito sericitizado e piritizado constituindo um beresito

A mobilidade dos ETR durante os processos hidrotermais tem sido avaliada em outras áreas mostrando comportamento variável; Taylor \& Fryer (1982) registraram uma lixiviação moderada de ETR em rochas propilitizadas associadas com mineralização do tipo cobre pórfiro; e Alderton et al. (1980), estudando rochas graníticas hidrotermalizadas na Cornuália, observaram uma perda de Eu durante a sericitização e empobrecimento dos ETRL concomitante com a cloritização.

Pode-se sugerir que a mobilidade dos ETR durante os processos hidrotermais será condicionada pela formação ou preservação de fases capazes de os conter e pela atividade de fluidos que possam formar complexos com esses elementos. Mineyev (1963) sugeriu a formação de complexos de metais alcalinos, ETR e flúor, enquanto Hildreth (1981) preconizou a maior estabilidade dos ETRP com flúor para explicar variaçōes na distribuição de ETR no Bishop Tuff.

COMPOSIÇÃO OUÍMICA. DE FASES HIDROTERMAIS DAS ROCHAS GRANÍTICAS Cloritas, sericitas, carbonatos e epídotos tiveram sua composição química investiga- 


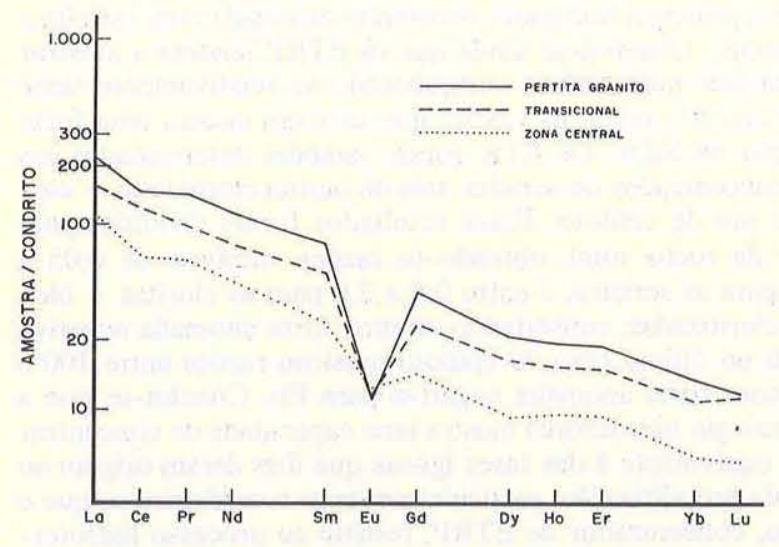

Figura 4 - Padrões de ETR normalizados pelos valores condríticos de Haskin et al. (1968) para os pertita granitos, granitóides transicionais e granitóides da zona central do Complexo Granítico Lavras

da em estudos de microssonda eletrônica e análise de concentrados minerais.

A análise química de três concentrados de sericita e os dados obtidos por microssonda eletrônica, tanto em amostras provenientes da zona central, como dos pertita granitos hidrotermalizados, indicaram a seguinte fórmula representativa da composição média das sericitas:

\begin{tabular}{|c|c|c|c|c|c|c|}
\hline \multicolumn{6}{|c|}{ Composição média } & $\Sigma$ \\
\hline $\mathrm{Si}$ & 6,7 & $\mathrm{Al}$ & 1,3 & & & 8,0 \\
\hline $\mathrm{Al}$ & 3,77 & $\mathrm{Fe}$ & 0,35 & $\mathrm{Mg}$ & 0,26 & 4,38 \\
\hline $\mathrm{Ca}$ & 0,02 & $\mathrm{Na}$ & 0,03 & $\mathrm{~K}$ & 1,70 & 1,75 \\
\hline $\mathrm{F}$ & 0,21 & $\mathrm{OH}$ & 2,18 & & & \\
\hline
\end{tabular}

A figura 5 a ilustra os padrões de ETR nos concentrados de sericita normalizados pelos valores condríticos de Haskin et al. (1968), indicando que a capacidade de concentrar ETR deste mineral é semelhante à dos feldspatos, exceto para o Eu.

Cloritas A composição química das cloritas foi obtida a partir dos dados de microssonda eletrônica uma vez que os concentrados apresentaram contaminação de biotita cloritizada.

Os valores médios obtidos permitem o cálculo da fórmula aproximada das cloritas, que, segundo a classificação sugerida por Bayliss (1975), são magnésio chamositas:

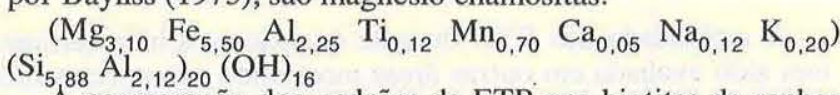

A comparação dos padrões de ETR nas biotitas de rochas inalteradas com os de cloritas mostra grande similaridade, constatando-se valores padronizados pelos teores na rocha total próximos de $1 \mathrm{com}$ anomalias negativas de Eu. Estudos dos elementos-traços indicam que o processo de cloritização das biotitas provocou forte decréscimo de $\mathrm{Ba}, \mathrm{Li}$ e $\mathrm{Rb}$.

Carbonatos Os carbonatos dos episienitos e de outros produtos de alteração nas rochas graníticas de Lavras do Sul foram estudados per difratometria de raios $\mathrm{X}$ e analisados após solubilização com ácido clorídrico, mostrando uma composição calcítica com teores de $\mathrm{MgO}$ inferiores a $0,1 \%$ em peso e de $\mathrm{FeO}$ (total) em torno de $2,45 \%$.

Epídotos Os ETR foram determinados em um concentrado de epídotos hidrotermais, tendo este mineral se mostrado um importante concentrador. A figura 5 b ilustra o padrão dos ETR normalizado pelos valores condríticos. A razão entre

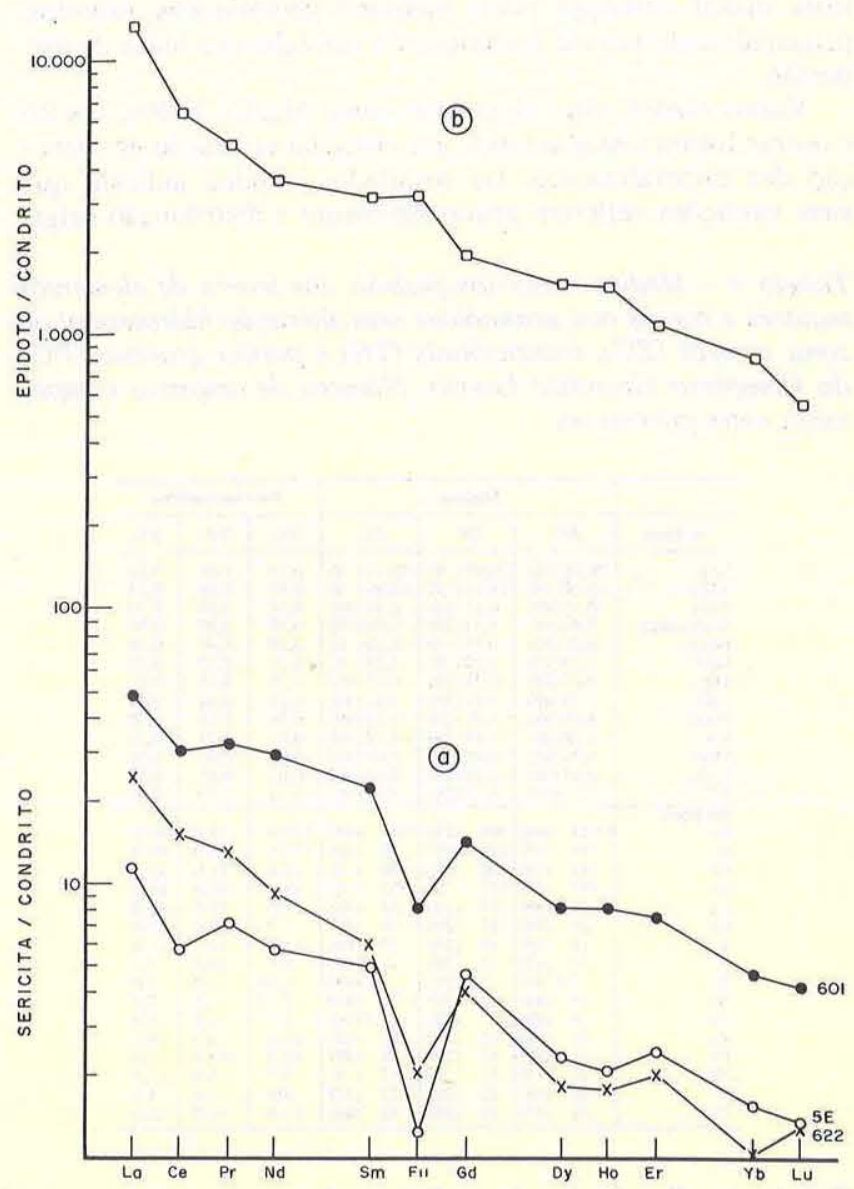

Figura 5 - Padrões de ETR normalizados pelos valores condríticos de Haskin et al. (1968) em concentrados de minerais de rochas hidrotermalizadas do Complexo Granítico Lavras: a. concentrados de sericita; $\mathbf{b}$. concentrado de epídoto

ETR no epídoto e na rocha total atinge valores da ordem de 100 a 200 para os ETR trivalentes e próximo de 30 para o Eu, caracterizando-se assim uma pronunciada anomalia negativa.

CONSIDERAÇÕES METALOGENÉTICAS A presença de mineralização dominantemente aurífera nos granitos alcalinos mais jovens - espacialmente associada com a presente nos granitóides da porção central e vulcânicas associadas, apresentando uma gama maior de elementos, $\mathrm{Mo}-\mathrm{Cu}-$ $\mathrm{Au}-(\mathrm{Pb}-\mathrm{Zn}-\mathrm{Ag})$ - tem sido reportada em outras regiões. Rozhkov (1970) afirma que depósitos auríferos com mais de uma fase de geração, sendo estas fases de idades distintas, constituem um grupo especial, destacando-se algumas mineralizações de $\mathrm{Cu}$-Mo sobre as quais se desenvolve mineralização aurífera mais jovem. Na região de Lavras do Sul, pode-se admitir que o magmatismo alcalino mais jovem teria remobilizado parcialmente depósitos preexistentes.

No que concerne à origem da mineralização ligada às rochas shoshoníticas, embora não seja objetivo deste trabalho discutir tal questão, cabe sugerir a possibilidade de um relacionamento com mineralização do tipo $\mathrm{Cu}$ - $\mathrm{Au}$-Mo pórfiro.

A comparação entre depósitos cobre pórfiro típicos (Mitchell \& Beckinsale 1982) com as mineralizações relacionadas às rochas shoshoníticas de Lavras do Sul envolve o reconhecimento de algumas diferenças importantes. Os primeiros são geralmente de afinidade cálcico-alcalina, embora sejam reconhecidos em rochas de afinidade shoshonítica (Dostal et al. 1977). Os depósitos típicos são cenozóicos e mesozóicos, e os pré-mesozóicos, como pode ser o caso da região aqui dis- 
cutida, apresentam, segundo Nielsen (1976), teores mais baixos.

Os cobre pórfiro típicos têm as zonas mineralizadas restritas a cúpulas de pequenos stocks, porém autores como Robinson \& Cook (1966), Corn (1975), Nielsen (1976) e Evans (1984) descrevem a presença de zonas mineralizadas ao longo de veios e zonas fraturadas na supra-estrutura vulcânica. Mitchell \& Beckinsale (1982) sugerem que os depósitos típicos predominam eın ambientes de arco magmático, enquanto Nielsen (1976) e Lowell (1974) registram a presença desse tipo de depósito confinado a zonas distensivas. Um fator de destaque é o volume considerável, geralmente aliado a baixos teores, nos depósitos cobre pórfiro clássicos. Esse fator é de difícil comparação até o momento para a região estudada já que os trabalhos de prospecção são insuficientes para definir com uma boa margem de segurança as características das mineralizaçōes da região de Lavras do Sul. O atual estado de conhecimento da mineralização na regiâo de Lavras do Sul permite sugerir que um modelo no estilo cobre pórfiro seja testado quando da realizaçảo de trabalhos de prospecção na área.
Pode-se supor que a mineralização principalmente filoniana reconhecida nessa área represente uma supra-estrutura vulcânica do sistema hidrotermal maior que estaria associado a intrusões rasas. A mineralização dos pertita granitos pode representä uma remobilização parcial desta fase de maior importância. O núcleo do Complexo Granítico Lavras, embora seja um alvo interessante, principalmente em suas porçōes mais profundamente hidrotermalizadas, não representa o tipo litológico com maior potencialidade para conter mineralização tipo cobre pórfiro.

Agradecimentos Os autores expressam seus agradecimentos à Financiadora de Estudos e Projetos (Finep), Conselho Nacional de Desenvolvimento Científico e Tecnológico $(\mathrm{CNPq})$ e Fundação de Amparo à Pesquisa do Estudo do Rio Grande do Sul (Fapergs), pelo apoio financeiro concedido. Nosso reconhecimento à professora Dione Alves Pintaúde e funcionários do Laboratório de Geoquímica do Instituto de Geociências da UFRGS, pelos trabalhos analíticos.

\section{REFERÊNCIAS BIBLIOGRÁFICAS}

ALDERTON, D.M.H.; PEARCE, J.A.; POTTS, P.J. 1980. Rare-earth mobility during granite alteration: evidence southwest England. Earth Planet. Sci. Lett., 49:149-165.

BAYLIS, P. 1975. Nomenclature of the trioctahedral chlorites. Canadian Miner., 13:178-180.

BERMAN, B. 1973. Mineralogical-geochemical characteristics of gold deposits developed at shallow depths. Intern. Geol. Rev., 15:784-790.

BOYLE, R. 1979. The geochemistry of gold and its deposits. Can. Geol. Surv., 280. $584 \mathrm{p}$

CORN, R.M. 1975. Alteration-mineralization zoning Red Mountain, Arizona. Econ. Geol., 70:1437-1447.

CUDDY, A.S. \& KESLER, S.E. 1982. Gold in the Granisle and Bell Copper porphyry deposits, British Columbia. In: LEVINSON, A.A. ed. Precious metals in the Northern Cordilhera. Association of Exploration Geochemistry. p. 139-155.

DOSTAL, J.; ZENTILLI, H.; CAELLES, J.C.; CLARK, A.H. 1977. Geochemistry and origin of volcanic rocks of the Andes $\left(26^{\circ}-28^{\circ} \mathrm{S}\right)$. Contrib. Mineral. Petrol., 63:113-128.

EVANS, A.M. 1984. An introduction to ore geology. London, Blackwell Scient. Publish. 231p.

GON̄I, J.C. 1961. O rapakivi Lavras, jazidas metalíferas associadas, Rio Grande do Sul, Brazil. Bol. Esc. Geol. UFRGS, 7.91p.

HASKIN, L.A.; HASKIN, M.A.; FREY, F.A. 1968. Relative and absolute terrestrial abundances of the rare earths. In: AHRENS, L.H. ed. Origin and distribution of the elements. Oxford: Pergamon. p. 889-912.

HILDRETH, W. 1981. Gradients in silicic magma chambens: Implications for lithospheric magmatism. J. Geophys. Res., 86(B11):10153-10192.

JOHN, E.C. 1975. Mineral zones of the Bingham district. In: BRAY, R E. \& WILSON, J.C. eds. Guidebook to the Bingham Mining District. Kennecott Copper Corporation. p. 59-72.

KAUL, P.F.T. \& ZIR Fo, A. 1974. Mineralizaçöes auríferas de Lavras do Sul, RS: tipos, controle tectônico, aspectos genéticos e guias para a localização de novos corpos mineralizados. In: CONGR BRAS. GEOL., 28, Porto Alegre. Anais... Porto Alegre, SBG. v. 6, p. 115-130.

LEROY, J. 1978. Métallogenèse des gisements d'uranium de la division de la Crouzille. Sci. Terre. Mens., 36. 276p.

LIMA, E.F. 1985. Petroquímica e prospeç̧āo litogeoquímica da área da Merita, regiäo de Volta Grande, Lavras do Sul, RS. Porto Alegre. 187 p. (Dissertação de Mestrado, UFRGS)

LIMA, E.F. \& NARDI, L.V.S, 1985. Geologia, petrografia petroquímica das rochas vulcânicas e tufáceas da regiāo de Volta Grande, Lavras do Sul, RS. Acta Geol.Leop., (20), p. 15-62.

LOWELL, 'J.D. 1974. Regional characteristics of porphyry copper deposits of Southwest. Econ. Geol., 69:601-617.
MEYER, C \& HEMLEY, JJ. 1967, Wall rock alteration. In: BARNES, H.L. ed. Geochemistry of hydrothermal ore deposits. Wiley Interscience. p. 166-235.

MINEYE MINEYEV, D.A. 1963. Geochemical differentiation of the rare earths, Geochemistry, 12:1129-1149.

MITCHELL, A.H.S. \& BECKINSALE, R.D. 1932. Mineral deposits associated with calc-alkaline rocks. In: THORPE, R.S. ed. Andesites. John Willey \& Sons. New York. p. 670-695.

NARDI, L.V.S. 1984. Geochemistry and petrology of the Lavras Granite Complex, RS, Brasil. Londres 268p. (Tese de doutorado, Universidade de Londres).

NARDI, L.V.S. \& LIMA, E.F. 1985. A associação shoshonítica de Lavras do Sul, RS. Rev. Bras. Geol., 15(2):139-146.

NIELSEN, R.L. 1976. Recent development in the study of porphyry copper geology. In: BROWN, A. ed. Porphyry deposits of the Canadian Cordillera. Can. Inst. Min. and Metall., Spec. vol. 15, p. $487-500$.

REISHEL, J.L. 1980. Mineralizações auríferas associadas ao Complexo Granítico de Lavras do Sul, RS. In: CONGR. BRAS. GEOL., 31, Baln. Camboriú, 1980. Anais... Baln. Camboriú, SBG. v. 3, p. $1700-1712$.

ROBINSON, R.F. \& COOK, A. 1966. The Stafford copper deposit Lone Star Mining District, Graham County, Arizona. In: TITLEY, S.R. \& HICKS, C.L. eds. Geology of the porphyry copper deposits, Southwestern North America. Tucson, Univ. Arizona Press, p. 251-266.

ROSE, A.W. \& BURT, D.M. 1979. Hydrothermal Alteration. In BARNES, H.L. ed. Geochemistry of hydrothermal ore deposits. New York. John Willey \& Sons. p. 173-235.

STRONG, D.F. 1982. Carbothermal metasomatism of alaskitic granite, St. Lawrence, Newfoundland, Canada. Chem. Geol., 35(1/2):97-144.

RIBEIRO, M. \& FANTINEL, L.M. 1978. Associação petrotectônica do Escudo Sul-riograndense. I Tabulação e Distribuição das Associaçōes Petrotectônicas do Escudo do Rio Grande do Sul. Iheringia, Ser. Geol., (5):19-54.

ROZHKOV, I.S. 1970. Genetic types of gold deposits and their setting in geotectonic structures. Intern. Geol.Rev., 12:921-929.

TAYLOR, R.P. \& FRYER, B.J. 1982. Rare earth element geochemistry as an aid to interpreting hydrothermal ore deposits. In: EVANS, A.M. ed. Metallization associated with a acid magmatism. new York. John Wiley \& Sons. p. 357-364.

TEIXEIRA, E.A. \& LEINZ, V. 1942. Ouro no bloco Butiá, RS. Rio de Janeiro, Div. Fom. Prod. Mineral DNPM. 81p. (Bol. 50).

MANUSCRITO 521 Recebido em 01 de fevereiro de 1988 Revisão aceita em 11 de maio de 1988 